\title{
Investigation and Management of Adnexal Masses in Pregnancy
}

\author{
João Cavaco-Gomes, ${ }^{1}$ Cátia Jorge Moreira, ${ }^{1}$ Anabela Rocha, ${ }^{1}$ Raquel Mota, ${ }^{1}$ \\ Vera Paiva, ${ }^{1}$ and Antónia Costa ${ }^{1,2}$ \\ ${ }^{1}$ Department of Obstetrics and Gynecology, São João Hospital Centre, 4200-319 Porto, Portugal \\ ${ }^{2}$ Porto Medical Faculty, 4200-319 Porto, Portugal
}

Correspondence should be addressed to João Cavaco-Gomes; cavacogomes@gmail.com

Received 5 December 2015; Accepted 16 March 2016

Academic Editor: Shunsuke Nakagawa

Copyright (C) 2016 João Cavaco-Gomes et al. This is an open access article distributed under the Creative Commons Attribution License, which permits unrestricted use, distribution, and reproduction in any medium, provided the original work is properly cited.

\begin{abstract}
Adnexal masses can be found in 0.19 to $8.8 \%$ of all pregnancies. Most masses are functional and asymptomatic and up to $70 \%$ resolve spontaneously in the second trimester. The main predictors of persistence are the size $(>5 \mathrm{~cm})$ and the imagiological morphocomplexity. Those that persist carry a low risk of malignancy (0 to $10 \%)$. Most malignant masses are diagnosed at early stages and more than $50 \%$ are borderline epithelial neoplasms. Ultrasound is the preferred method to stratify the risk of complications and malignancy, allowing medical approach planning. Pregnancy and some gestational disorders may modify the levels of tumor markers, whereby their interpretation during pregnancy should be cautious. Large masses are at increased risk of torsion, rupture, and dystocia. When surgery is indicated, laparoscopy is a safe technique and should ideally be carried out in the second trimester of pregnancy.
\end{abstract}

\section{Introduction}

Adnexal masses originate in the ovaries, fallopian tubes, or surrounding tissue. They may present as different histological types and their clinical significance may vary largely depending mainly on tumor size, clinical presentation, and risk of malignancy. Adnexal masses can be found in women of any age, and pregnancy is not only no exception, but also a period associated with some particular adnexal formations. The systematic use of ultrasound in the first trimester of pregnancy led to increased identification of asymptomatic and once clinically undetectable adnexal masses, bringing to debate their guidance and their implications during pregnancy.

\section{Materials and Methods}

The aim of this study was to review evidence about epidemiology, clinical presentation, medical approach, and management of adnexal masses in pregnancy.

In order to access evidence about epidemiology, natural history, and outcomes, the PubMed Central database was searched to identify studies reporting cases of adnexal masses in pregnancy. The search was conducted using two sets of keywords: (1) "adnexal mass" and "pregnancy"; (2) "ovarian mass" and "pregnancy". The database was searched without restriction on date of publication. Case reports were not considered. Additional relevant articles were garnered from the references of included papers. Eligibility for inclusion was limited to papers written in English and French. Each abstract obtained through the electronic database was evaluated for relevance, and the full text of each relevant abstract was obtained and evaluated for inclusion. From 137 abstracts initially selected, 72 full-text articles were reviewed for eligibility and 37 were finally included in this review: 29 retrospective studies, 5 prospective studies, and 3 review articles.

\section{Epidemiology}

The prevalence of adnexal masses in pregnancy is estimated to be around $0.19-8.8 \%$ [1]. Most cases are diagnosed in the first trimester, and the incidence appears to gradually decrease with increasing gestational age (Table 1) [2-6]. 
TABLE 1: Proportion of adnexal masses detected throughout pregnancy [2-6].

\begin{tabular}{lc}
\hline Period & $\begin{array}{c}\text { Proportion of cases } \\
\text { diagnosed }\end{array}$ \\
\hline 1st trimester & $21.4-75.7 \%$ \\
2nd trimester & $10.9-44.4 \%$ \\
3rd trimester & $4-22.2 \%$ \\
Postpartum & $0-7.1 \%$ \\
\hline
\end{tabular}

\section{Clinical Presentation}

Adnexal masses in pregnancy are mostly asymptomatic, being diagnosed as ultrasound or surgical findings. During C-sections adnexal masses are found in about $0.3 \%$ of the cases $[7,8]$. Only a minor proportion of women have symptoms, most frequently pain (Table 2). In about 31 to $72 \%$ of cases there will be a spontaneous resolution of the mass (Table 2). The most important predictors for persistence are imagiological morphocomplexity and dimension larger than $5 \mathrm{~cm}$ [9]. Masses that persist throughout pregnancy tend to be displaced upwardly out of the pelvic cavity, as the uterus increases in size. Occasionally, they may be incarcerated in the Douglas pouch throughout pregnancy, with subsequent compression of adjacent structures, namely, urinary tract and lower digestive tract, with subsequent symptoms from these organs. The incarceration of the mass within the pelvis can also be responsible for labor dystocia through obstruction the descent of the presenting fetal part.

\section{Histology (Table 3)}

Most adnexal masses in pregnancy are benign and mainly represented by functional cysts (follicular, corpus luteum, and theca lutein cysts), teratomas, and cystadenomas. Nevertheless, malignant adnexal tumors should also be considered. The risk of malignancy is estimated around $0-10 \%[3,7,9-$ 16]. Main series refer that borderline ovarian tumors account for over $50 \%$ of the malignant tumors $[4,9,14,16,17]$.

\section{Evaluation}

Once an adnexal mass is diagnosed, regardless of the associated symptoms (excepting cases of acute abdomen), clinical approach should involve assessment of malignancy risk as well as predictors of tumor persistence and complications. Imaging study (ultrasound with doppler fluxometry and magnetic resonance imaging) associated with serum tumor markers plays a key role in this setting.

6.1. Ultrasound. Usually adnexal masses in pregnancy are imagiological findings, but when detected by palpation on physical exam, ultrasound should be the first step to characterize the lesion. Transabdominal and/or transvaginal ultrasound allows morphodimensional evaluation and assessment of mass vascularization and growth, as well as observation of the contralateral ovary and detection of other malignant signs, such as the presence of ascites and peritoneal carcinomatosis [18, 33]. Several ultrasonographic features were associated, in nonpregnant women, with an increased risk of malignancy, such as irregular solid tumor, multilocular and irregular masses with more than $10 \mathrm{~cm}$, septa thicker than 2-3 $\mathrm{mm}$, presence of more than three papillary projections, exuberant blood flow, and presence of ascites or peritoneal masses [34, 35]. Application of IOTA (International Ovarian Tumor Analysis) group rules in ultrasound evaluation of premenopausal and postmenopausal women has demonstrated high sensitivity and specificity at stratifying the malignancy risk $[36,37]$. Although there are no studies demonstrating the performance of these models in pregnancy, the previously listed malignant sonographic features seem to be also valid in pregnancy $[5,9,10,28,29]$.

Nevertheless, ultrasound evaluation of adnexal masses in pregnant women has some limitations. Increased uterine volume makes evaluation difficult after 20 weeks of gestation. Furthermore, fluxometric parameters may be difficult to appreciate in pregnancy, both by the increased flow velocity and lower vascular resistance found at pregnancy and by the significant overlap in fluxometric pattern between benign and malignant masses, with an estimated false positive rate of $48-49 \%[38,39]$. In addition, germ cell tumors, one of the most common histological types, have less defined malignant sonographic features.

6.2. Magnetic Resonance Imaging and Computed Tomography. Magnetic resonance imaging (MRI) should be reserved for those cases in which ultrasound evaluation is inconclusive or insufficient for clinical decision planning [40]. MRI is particularly useful for characterizing large masses, evaluating their relationship with adjacent structures (namely, adjacent organ invasion and compression), and differentiating masses appearing to have adnexal location on ultrasound but actually having a different organ filiation [33]. MRI is also useful, when an advanced stage malignant tumor is suspected, requiring the assessment of the retroperitoneum, abdominopelvic cavity, and lymph nodes. MRI appears to be safe in pregnancy, but caution is advised for its use in first trimester, as well as for the use of gadolinium contrast, because of the potential fetal risks [41].

Despite its better performance at retroperitoneal and lymph node evaluation, Computed Tomography (CT) plays a limited role in pregnancy, because of the potential risk associated with fetal irradiation [32]. Nevertheless, it may be useful for thoracic assessment in case of malignant lesions, provided that abdominal radiation protection is used.

6.3. Tumor Markers. The interpretation of tumor markers serum levels in pregnant women requires caution, since they may be physiologically increased during certain stages of pregnancy (Table 4). This is particularly true regarding some oncofetal antigens (alpha-fetoprotein, human chorionic gonadotropin, and CA125), which are involved in biological functions associated with development, differentiation, and fetal maturation [21-24]. Moreover, placental and fetal anomalies (such as preeclampsia, 21 trisomy, and neural tube defects) may also present with an abnormal increase of these 
TABLE 2: Clinical presentation and frequency of spontaneous resolution of adnexal masses in pregnancy $[3,4,9-11,18-20]$.

\begin{tabular}{|c|c|c|c|c|}
\hline & $N$ & Asymptomatic & Symptomatic & $\begin{array}{l}\text { Spontaneous } \\
\text { resolution }\end{array}$ \\
\hline $\begin{array}{l}\text { Bernhard et al., } 1999 \text { [9] } \\
\text { (>5 cm/complex) }\end{array}$ & 102 & $78.4 \%$ & $21.6 \%$ (pain or palpable mass) & $68.6 \%$ \\
\hline Zanetta et al., 2003 [18] & 79 & $86.1 \%$ & $13.9 \%$ (pain) & $51 \%$ \\
\hline Agarwal et al., 2003 [19] & 14 & $35.6 \%$ & $\begin{array}{l}50 \% \text { (pain or discomfort) } \\
14.2 \% \text { (larger than expected uterus) }\end{array}$ & NA \\
\hline Condous et al., 2004 [20] & 161 & $43.7 \%$ & $56.3 \%$ (pain or genital bleeding) & $71.7 \%$ \\
\hline $\begin{array}{l}\text { Schmeler et al., } 2005[10] \\
(>5 \mathrm{~cm})\end{array}$ & 59 & $92 \%$ & $8 \%$ (pain) & $1,7 \%$ \\
\hline Kumari et al., 2006 [11] & 20 & $50 \%$ & $\begin{array}{l}35 \% \text { (pain) } \\
15 \%(\mathrm{NE})\end{array}$ & NA \\
\hline Balci et al., 2008 [3] & 36 & $30.6 \%$ & $69,4 \%$ (pain) & NA \\
\hline $\begin{array}{l}\text { Aggarwal and Kehoe, } 2011[4] \\
(\text { review })^{\odot}\end{array}$ & 809 & $65.4 \%$ & $\begin{array}{c}16.8 \% \text { (pain) } \\
9 \% \text { (bleeding/dystocia/rupture) }\end{array}$ & $30.7 \%$ \\
\hline
\end{tabular}

NE: not specified; NA: not applicable to study design. $\odot_{\text {Review of studies including only surgically managed cases of both benign and malignant tumors }}$ (includes the other studies quoted here, except Agarwal et al. (2003) [19] and Kumari et al. (2006) [11]).

markers $[21,25]$. The main interest of tumor markers seems to be the differentiation between primary and secondary adnexal tumors and the possibility to monitor their levels to evaluate the therapeutic response and the risk of relapse [32].

\section{Complications (Table 5)}

Most adnexal masses in pregnancy are benign and physiological. Spontaneous resolution is the rule. However, the risk of malignancy is not negligible and other complications may arise such as torsion, rupture, and bleeding. On the other hand, the associated obstetric risk, particularly the risk of miscarriage, preterm labor, and mechanical dystocia, should be also kept in mind. Table 5 summarizes the frequency of the most frequently described complications.

7.1. Adnexal Torsion. Adnexal torsion is one of the most frequent gynecological surgical emergencies and about 10 to $20 \%$ occur in pregnancy [42-44]. It is defined as complete or partial rotation of the ovarian vascular pedicle on its long axis, usually involving the tube and ovary. If torsion persists over 36 to 48 hours, it is considered a surgical emergency due to the risk of irreversible damage to the functional ovarian tissue [45-47].

Different factors have been associated with an increased risk of adnexal torsion in pregnancy, including gestational age (58\% of cases in the first trimester) [2], mass size (greater risk for masses with diameters between 6 and $10 \mathrm{~cm}$ ) $[2,15]$, and ovarian stimulation (73\% of cases associated with the use of assisted reproductive technology) [48].

Clinical presentation is not specific and usually includes abdominal pain, nausea, vomiting, and eventually fever and leukocytosis [48]. Diagnosis requires a high index of suspicion, but some imaging signs are suggestive, such as larger and more rounded ovary, heterogeneous stromal echogenicity, multiple small size follicles in periphery, decreased intraparenchymal blood flow, and the "Whirlpool sign."
Treatment of this complication requires surgery. After detorsion of the adnexa, restoration of blood flow should be assessed: if recoloring and decreasing edema are noted, one should only proceed to the aspiration of the hemorrhagic content. Bivalving technique is also described for vascular decompression and restoration of ovarian blood flow [49]. In case of persisting signs of ischemia, adnexectomy is mandatory.

The risk of rupture $(0-5 \%)[11,16]$ and other mechanical complications such as hemorrhage and obstruction (9\%) [4] is less frequently described.

7.2. Malignancy. The occurrence of cancer in pregnancy is an uncommon event, with an overall estimated incidence of 0.02 to $1 \%[50,51]$. Although rare, ovarian cancer is the second most common gynecological cancer in pregnancy with an incidence of $1: 12.500$ to $1: 25,000$ pregnancies [52].

The proportion of adnexal masses in pregnancy which correspond to malignant tumors varies considerably among published series ( 0 to $10 \%$, Table 3 ). It has been estimated that on average 1 out of every 16,000 pregnancies is complicated by an adnexal malignant tumor [53].

Besides the previously mentioned sonographic features suggestive of malignancy, in pregnancy, the lesion size (different cut-offs have been proposed, Table 6) and a growth rate greater than $0.35 \mathrm{~cm} /$ week (10 times greater risk of malignancy) are also of note [15].

At younger age groups the most common malignant tumors of the ovary are germ cell tumors and epithelial tumors, and in pregnancy the latter may be even more common than the former (Table 3) [4]. Contrarily to the nonpregnant women, the majority of ovarian tumors are diagnosed in the early stages ( $80 \%$ in stage 1 of FIGO), with a large proportion of those corresponding to borderline tumors $[2,4,15]$. 


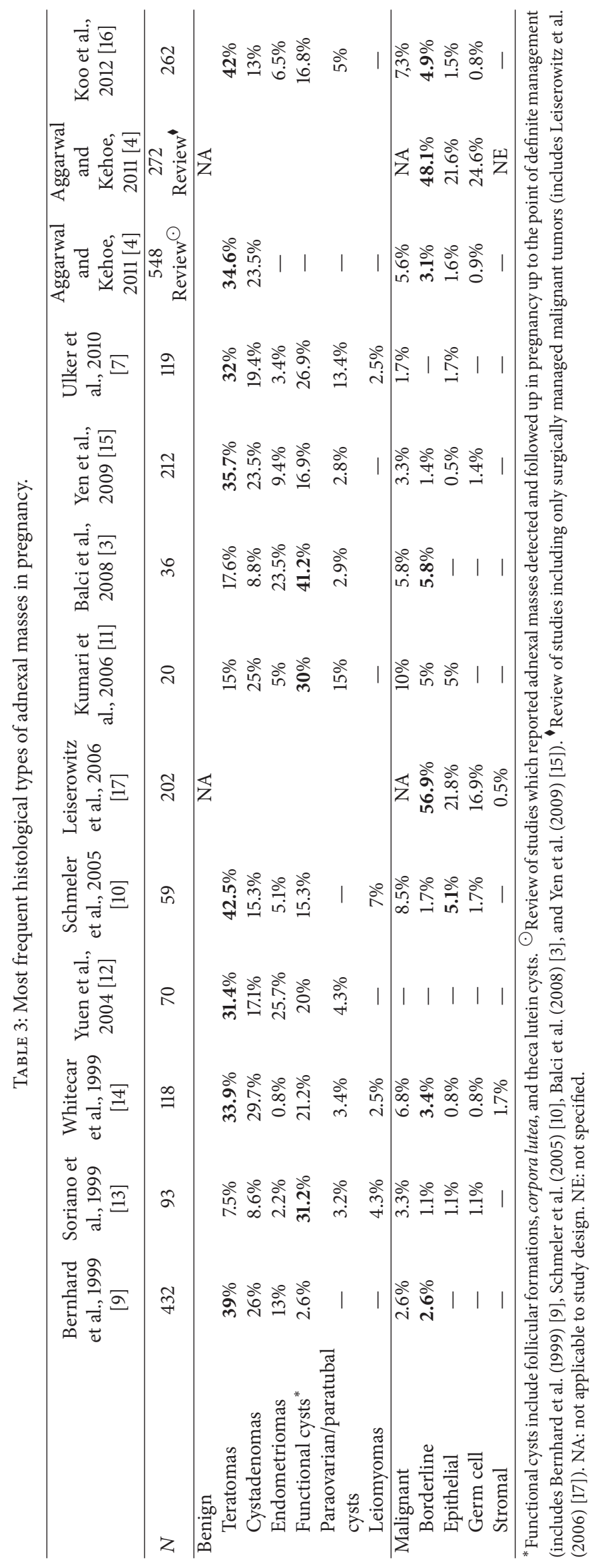


TABLE 4: Tumor markers in pregnancy [21-27].

\begin{tabular}{|c|c|c|c|}
\hline Tumor markers & $\begin{array}{l}\text { Associated histological types of } \\
\text { ovarian and other tumors }\end{array}$ & Changes in pregnancy & Observations \\
\hline CA 125 & Ovarian epithelial tumors & $\begin{array}{l}\text { Increased in 1st trimester: } \\
\text { (i) Starts at } 30-40 \mathrm{~d} \text { after LMP, } \\
\text { peaks at } 35-60 \mathrm{~d} \\
\text { (ii) May reach } 1250 \mathrm{U} / \mathrm{mL} \\
\text { (iii) Decrease at the end of } 1 \mathrm{st} \mathrm{T}\end{array}$ & $\begin{array}{l}\text { Useful as tumor marker for } \\
\text { ovarian epithelial tumors } \\
\text { between } 15 \text { weeks of gestation } \\
\text { and delivery }\end{array}$ \\
\hline CEA & $\begin{array}{l}\text { Epithelial tumors (particularly, } \\
\text { colorectal carcinoma) }\end{array}$ & $\begin{array}{l}\text { Serum levels not influenced by } \\
\text { pregnancy }\end{array}$ & $\begin{array}{l}\text { Can be used as tumor marker in } \\
\text { pregnancy }\end{array}$ \\
\hline CA 19.9 & $\begin{array}{l}\text { Gastrointestinal, pancreatic, and } \\
\text { other adenocarcinomas } \\
\text { Ovarian mucinous tumors }\end{array}$ & $\begin{array}{l}\text { Mildly increased levels with } \\
\text { increased gestational age, but } \\
\text { never exceeding the normal } \\
\text { range }\end{array}$ & $\begin{array}{l}\text { Can be used as tumor marker in } \\
\text { pregnancy }\end{array}$ \\
\hline b-HCG & $\begin{array}{l}\text { Germ cell tumors (particularly, } \\
\text { choriocarcinoma) }\end{array}$ & $\begin{array}{l}\text { Physiologically increased during } \\
\text { pregnancy }\end{array}$ & $\begin{array}{l}\text { Not possible to use as tumor } \\
\text { marker during pregnancy }\end{array}$ \\
\hline AFP & $\begin{array}{l}\text { Germ cell tumors (endodermal } \\
\text { sinus tumor, embryonal } \\
\text { carcinoma, and mixed tumors) }\end{array}$ & $\begin{array}{l}\text { Physiologically increased during } \\
\text { pregnancy } \\
\text { Abnormally increased in NTD } \\
\text { and decreased in Down } \\
\text { syndrome }\end{array}$ & $\begin{array}{l}\text { Serum levels usually }<500 \mathrm{ng} / \mathrm{mL} \\
\text { in pregnancy complicated by } \\
\text { NTD and }>1000 \mathrm{ng} / \mathrm{mL} \text { in germ } \\
\text { cell tumors }\end{array}$ \\
\hline $\mathrm{LDH}$ & Dysgerminomas & $\begin{array}{l}\text { Increased in pregnancy diseases } \\
\text { (severe preeclampsia, HELLP } \\
\text { syndrome) }\end{array}$ & \\
\hline Inhibin A & $\begin{array}{l}\text { Granulosa cell tumors; mucinous } \\
\text { carcinoma }\end{array}$ & $\begin{array}{l}\text { Increased in 1st trimester } \\
\text { (produced by developing } \\
\text { placenta) } \\
\text { Abnormally increased in Down } \\
\text { syndrome }\end{array}$ & $\begin{array}{l}\text { (i) Used in 2nd trimester for } \\
\text { Down syndrome screening } \\
\text { (ii) Increased levels require fetal } \\
\text { and ovarian evaluation }\end{array}$ \\
\hline $\mathrm{He} 4$ & $\begin{array}{l}\text { Serous, endometrioid, and clear } \\
\text { cell epithelial tumors }\end{array}$ & $\begin{array}{l}\text { Lower levels in pregnant women } \\
\text { Mildly increased in 3rd T } \\
\text { compared to } 2 \text { nd T } \\
\text { Elevated levels can also be found } \\
\text { in PTD }\end{array}$ & $\begin{array}{l}\text { Promising tumor marker, but its } \\
\text { value in pregnancy is not } \\
\text { established }\end{array}$ \\
\hline
\end{tabular}

NTD: neural tube defects; AFP: alfa-fetoprotein; LMP: last menstrual period; T: trimester; d: day; PTD: preterm delivery.

TABle 5: Frequency of complications of adnexal masses in pregnancy.

\begin{tabular}{lc}
\hline Complications & Frequency \\
\hline Torsion $[2,3,5,9-11,14,15,20]$ & $1-27.7 \%$ \\
Rupture $[11,16]$ & $0-5 \%$ \\
Malignancy $[3,7,9-16]^{*}$ & $0-10 \%$ \\
Abortion $[3-5,10,14,28-31]$ & $0-6 \%$ \\
Preterm delivery $[3-5]$ & $5.8-10.4 \%$ \\
\hline
\end{tabular}

${ }^{*}$ Malignancy, including borderline tumors.

7.3. Obstetric Outcome. Depending on their size and location, adnexal masses may be associated with a poor obstetric outcome caused by a mechanical effect. They have been linked to an increased risk of miscarriage, preterm delivery, and dystocia. In addition, prenatal surgical approach to these lesions, either at emergency situations (e.g., ovarian torsion) or on a scheduled basis, is also associated with a significant obstetrical risk (Table 7).

\section{Treatment}

8.1. Expectant Management. As mentioned above, most identified adnexal masses in pregnancy resolve spontaneously, requiring no intervention. Therefore, expectant management towards an adnexal cyst in the first trimester should be encouraged, as long as there is a low index of suspicion for malignancy or complications (such as torsion or rupture). In case of persistence, the risk of complications such as acute abdomen, dystocia, or malignancy must be weighed against possible risks of an antepartum surgery. Given a sonographic low risk of malignancy without predictors of complications, clinical and imaging surveillance until postpartum period must be considered and has been supported by the existing retrospective studies $[10,17,18]$.

8.2. Surgery. Surgical treatment is indicated in cases of acute abdomen, severe clinical manifestations (e.g., hydronephrosis), strong suspicion of malignancy, or anticipated risk of dystocia. Surgical intervention, if not urgent, should in general be delayed until the second trimester because (1) it avoids 
TABLE 6: Size of the adnexal mass and risk of malignancy.

\begin{tabular}{|c|c|c|c|}
\hline & $N$ & Cut-off & Estimated risk \\
\hline Sherard III et al., 2003 [5] & 60 & $<6 \mathrm{~cm}$ & $\begin{array}{l}\text { Average lesion size: benign } 7.6 \mathrm{~cm} \text { versus malign } 11.5 \mathrm{~cm}(p<0.05) \text {; all } \\
\text { masses }<6 \mathrm{~cm} \text { were benign }\end{array}$ \\
\hline $\begin{array}{l}\text { Schmeler et al., } 2005[10] \\
(\text { masses }>5 \mathrm{~cm})\end{array}$ & 59 & - & Average lesion size: benign $7.3 \mathrm{~cm}$ versus malign $10,2 \mathrm{~cm}(p=0.29)$ \\
\hline Schwartz et al., 2009 [6] & Review & $>7 \mathrm{~cm}$ & Refer to only increased risk of malignancy \\
\hline Yen et al., 2009 [15] & 212 & $\geq 10 \mathrm{~cm}$ & OR: $11.2 ; p<0.01$ \\
\hline Koo et al., 2011 [2] & 470 & $>15 \mathrm{~cm}$ & OR: $12.36 ; p=0.001$ \\
\hline Hoover and Jenkins, 2011 [32] & Review & $\geq 5 \mathrm{~cm}$ & Refer to only increased risk of malignancy \\
\hline
\end{tabular}

TABLE 7: Obstetric impact of adnexal masses in pregnancy.

\begin{tabular}{|c|c|c|c|c|}
\hline & $N$ & Abort. & PTD & Observations \\
\hline Platek et al., 1995 [31] & 31 & $3.2 \%$ & - & $59 \%$ antenatal surgery \\
\hline Bromley and Benacerraf, 1997 [28] & 125 & $0 \%$ & - & $19 \%$ antenatal surgery \\
\hline Whitecar et al., 1999 [14] & 130 & $1.5 \%$ & - & $66 \%$ antenatal surgery \\
\hline Usui et al., 2000 [29] & 69 & $3.3 \%$ & - & $99 \%$ antenatal surgery \\
\hline Sherard III et al., 2003 [5] & 60 & $4.7 \%$ & $9 \%$ & $100 \%$ antenatal surgery \\
\hline Schmeler et al., 2005 [10] & 59 & $0 \%$ & - & $29 \%$ antenatal surgery \\
\hline Balci et al., 2008 [3] & 36 & $2.9 \%$ & $5.8 \%$ & $94 \%$ antenatal/peripartum surgery \\
\hline Aggarwal and Kehoe, 2011 (review) ${ }^{\odot}$ [4] & 498 & $6 \%$ & $10.4 \%$ & $100 \%$ antenatal/peripartum surgery \\
\hline
\end{tabular}

Abort.: abortion; PTD: preterm delivery. $\odot_{\text {Review of studies including only surgically managed cases of both benign and malignant tumors (includes Whitecar }}$ et al. (1999) [14] and Sherard III et al. (2003) [5]).

the period of greatest risk of drug-induced teratogenicity; (2) spontaneous fetal losses due to intrinsic fetal abnormalities have already occurred; (3) the function of corpus luteum has been replaced by the placenta; (4) most functional cysts have disappeared; (5) an acceptable operative field is still available, allowing minimal uterine manipulation and low risk of obstetric complications. A later surgery in pregnancy, at the end of second trimester or at third trimester, may be technically more difficult and result in an adverse obstetric outcome. When indicated for other reasons, cesarean section may also be an opportunity for the surgical management of adnexal masses.

The type of surgical approach, laparotomy, or laparoscopy, has also been subject of debate in the literature. The advantages of laparoscopy are largely the same as for nonpregnant women and include lower operative pain; minor bleeding; early ambulation, reducing the risk of thromboembolic events; early resumption of bowel transit; shorter hospital stay; faster return to activities of daily living; lower risk of surgical wound infection; and less uterine manipulation, with a consequently theoretical lower risk of preterm delivery.

However, some concerns about a laparoscopic approach in pregnancy have been raised: high intra-abdominal pressure may compromise placental perfusion; maternal conversion of carbon dioxide into carbonic acid can result in fetal acidosis; pregnant uterus may be injured during insertion of Veress needle or trocars [54].

Although there are no prospective studies assessing the safety of laparoscopy in pregnancy, main published series show that it is technically feasible and as safe as laparotomy, with a conversion to laparotomy rate lower than $10 \%$ [13, 16, 55-59]. The Society of American Gastrointestinal and Endoscopic Surgeons (SAGES) stated that laparoscopy can be safely performed in any trimester of pregnancy [60]. This society has developed some technical recommendations for performing laparoscopy in pregnant women, which include the following: (1) patient must be positioned in left lateral position (to minimize inferior vena cava compression); (2) initial access to the abdominal cavity can be safely performed by open surgery (Hasson) with a Veress needle or by optical trocar, as long as the location takes into account the uterine fundal height and previous incisions; (3) CO2 insufflation with $10-15 \mathrm{mmHg}$ pressure is safe, but intraoperative CO2 monitoring by capnography is recommended; (4) pneumatic compression devices are recommended in intra- and postoperative period as well as early postoperative ambulation (for venous thromboembolism prophylaxis); (5) tocolytics should not be used prophylactically but should be considered perioperatively in the presence of preterm labor signs [60].

When malignancy is suspected, assertive information must be offered to the pregnant woman. Only after precise and clear discussion of all the viable options (not neglecting the risks and benefits towards the obstetrics and oncological outcomes) can the medical approach be guided by the patient decision. Clinical management can vary widely and many factors must be taken into account, namely, (1) gestational age (previability, viability far from term and near term); (2) oncological disease status (suspected malignancy and with 
disease confined to the ovary, extraovarian dissemination with carcinomatosis but without intraorgan spread or intraparenchymatous organ spread). These factors will interfere with the treatment options (such as complete surgical staging, cytoreductive surgery followed by adjuvant chemotherapy, and neoadjuvant chemotherapy followed by surgery), with relevant impact on neonatal and maternal morbimortality. The surgery is usually performed by laparotomy, but laparoscopic approach may be considered as long as complete staging is respected and all the standard precautions to avoid spread of malignant cells during the procedure are taken (in particular, avoiding tumor rupture during handling of the specimen) [61-63]. The discussion of specific surgical and medical management of ovarian malignancy in pregnancy is beyond the scope of this review.

\section{Conclusions}

Most adnexal masses, which arise in pregnancy, are functional and asymptomatic and resolve spontaneously. Persistent adnexal masses carry a low risk of malignancy, and ultrasonography is the preferred method to assess this risk. In asymptomatic pregnant women without predictors of complications and sonographic findings suggestive of malignancy, expectant management is generally the most suitable option. On the other hand when strong clinical suspicion of malignancy or presence of acute abdomen or severe clinical manifestations occur, surgical treatment is indicated by laparotomy or laparoscopy. Laparoscopy was shown to be a safe and technically feasible approach, with the advantages of a minimally invasive surgery.

\section{Competing Interests}

The authors declare that they have no competing interests.

\section{References}

[1] T. Bignardi and G. Condous, "The management of ovarian pathology in pregnancy," Best Practice and Research: Clinical Obstetrics and Gynaecology, vol. 23, no. 4, pp. 539-548, 2009.

[2] Y. J. Koo, T. Kim, J. Lee et al., "Risk of torsion and malignancy by adnexal mass size in pregnant women," Acta Obstetricia et Gynecologica Scandinavica, vol. 90, no. 4, pp. 358-361, 2011.

[3] O. Balci, K. Gezginc, R. Karatayli, A. Acar, C. Celik, and M. C. Colakoglu, "Management and outcomes of adnexal masses during pregnancy: a 6-year experience," Journal of Obstetrics and Gynaecology Research, vol. 34, no. 4, pp. 524-528, 2008.

[4] P. Aggarwal and S. Kehoe, "Ovarian tumours in pregnancy: a literature review," European Journal of Obstetrics Gynecology and Reproductive Biology, vol. 155, no. 2, pp. 119-124, 2011.

[5] G. B. Sherard III, C. A. Hodson, H. J. Williams, D. A. Semer, H. A. Hadi, and D. L. Tait, "Adnexal masses and pregnancy: a 12-year experience," American Journal of Obstetrics and Gynecology, vol. 189, no. 2, pp. 358-362, 2003.

[6] N. Schwartz, I. E. Timor-Tritsch, and E. Wang, "Adnexal masses in pregnancy," Clinical Obstetrics and Gynecology, vol. 52, no. 4, pp. 570-585, 2009.
[7] V. Ulker, A. Gedikbasi, C. Numanoglu, S. Saygi, H. Aslan, and A. Gulkilik, "Incidental adnexal masses at cesarean section and review of the literature," Journal of Obstetrics and Gynaecology Research, vol. 36, no. 3, pp. 502-505, 2010.

[8] E. Baser, S. Erkilinc, S. Esin et al., "Adnexal masses encountered during cesarean delivery," International Journal of Gynecology and Obstetrics, vol. 123, no. 2, pp. 124-126, 2013.

[9] L. M. Bernhard, P. K. Klebba, D. L. Gray, and D. G. Mutch, "Predictors of persistence of adnexal masses in pregnancy," Obstetrics and Gynecology, vol. 93, no. 4, pp. 585-589, 1999.

[10] K. M. Schmeler, W. W. Mayo-Smith, J. F. Peipert, S. Weitzen, M. D. Manuel, and M. E. Gordinier, "Adnexal masses in pregnancy: surgery compared with observation," Obstetrics and Gynecology, vol. 105, no. 5, part 1, pp. 1098-1103, 2005.

[11] I. Kumari, S. Kaur, H. Mohan, and A. Huria, "Adnexal masses in pregnancy: a 5-year review," The Australian and New Zealand Journal of Obstetrics and Gynaecology, vol. 46, no. 1, pp. 52-54, 2006.

[12] P. M. Yuen, P. S. Ng, P. L. Leung, and M. S. Rogers, "Outcome in laparoscopic management of persistent adnexal mass during the second trimester of pregnancy," Surgical Endoscopy and Other Interventional Techniques, vol. 18, no. 9, pp. 1354-1357, 2004.

[13] D. Soriano, Y. Yefet, D. S. Seidman, M. Goldenberg, S. Mashiach, and G. Oelsner, "Laparoscopy versus laparotomy in the management of adnexal masses during pregnancy," Fertility and Sterility, vol. 71, no. 5, pp. 955-960, 1999.

[14] P. Whitecar, S. Turner, and K. Higby, "Adnexal masses in pregnancy: a review of 130 cases undergoing surgical management," American Journal of Obstetrics and Gynecology, vol. 181, no. 1, pp. 19-24, 1999.

[15] C.-F. Yen, S.-L. Lin, W. Murk et al., "Risk analysis of torsion and malignancy for adnexal masses during pregnancy," Fertility and Sterility, vol. 91, no. 5, pp. 1895-1902, 2009.

[16] Y. Koo, H. J. Kim, K. Lim et al., "Laparotomy versus laparoscopy for the treatment of adnexal masses during pregnancy," Australian and New Zealand Journal of Obstetrics and Gynaecology, vol. 52, no. 1, pp. 34-38, 2012.

[17] G. S. Leiserowitz, G. Xing, R. Cress, B. Brahmbhatt, J. L. Dalrymple, and L. H. Smith, "Adnexal masses in pregnancy: how often are they malignant?" Gynecologic Oncology, vol. 101, no. 2, pp. 315-321, 2006.

[18] G. Zanetta, E. Mariani, A. Lissoni et al., "A prospective study of the role of ultrasound in the management of adnexal masses in pregnancy," BJOG: An International Journal of Obstetrics and Gynaecology, vol. 110, no. 6, pp. 578-583, 2003.

[19] N. Agarwal, Parul, A. Kriplani, N. Bhatla, and A. Gupta, "Management and outcome of pregnancies complicated with adnexal masses," Archives of Gynecology and Obstetrics, vol. 267, no. 3, pp. 148-152, 2003.

[20] G. Condous, A. Khalid, E. Okaro, and T. Bourne, "Should we be examining the ovaries in pregnancy? Prevalence and natural history of adnexal pathology detected at first-trimester sonography," Ultrasound in Obstetrics and Gynecology, vol. 24, no. 1, pp. 62-66, 2004.

[21] A. Sarandakou, E. Protonotariou, and D. Rizos, "Tumor markers in biological fluids associated with pregnancy," Critical Reviews in Clinical Laboratory Sciences, vol. 44, no. 2, pp. 151178, 2007.

[22] N. Aslam, C. Ong, B. Woelfer, K. Nicolaides, and D. Jurkovic, "Serum CA125 at 11-14 weeks of gestation in women with morphologically normal ovaries," BJOG: An International Journal of Obstetrics \& Gynaecology, vol. 107, no. 5, pp. 689-690, 2000. 
[23] A. Sarandakou, A. Kontoravdis, Z. Kontogeorgi, D. Rizos, and I. Phocas, "Expression of CEA, CA-125 and SCC antigen by biological fluids associated with pregnancy," European Journal of Obstetrics and Gynecology and Reproductive Biology, vol. 44, no. 3, pp. 215-220, 1992.

[24] A. Sarandakou, I. Phocas, D. Botsis, D. Rizos, E. Trakakis, and A. Chryssikopoulos, "Vaginal fluid and serum CEA, CA125 and SCC in normal conditions and in benign and malignant diseases of the genital tract," Acta Oncologica, vol. 36, no. 7, pp. 755-759, 1997.

[25] A. Gagnon, R. D. Wilson, F. Audibert et al., "Obstetrical complications associated with abnormal maternal serum markers analytes," Journal of Obstetrics and Gynaecology Canada, vol. 30, no. 10, pp. 918-932, 2008.

[26] R. G. Moore, M. C. Miller, E. E. Eklund, K. H. Lu, R. C. Bast Jr., and G. Lambert-Messerlian, "Serum levels of the ovarian cancer biomarker HE4 are decreased in pregnancy and increase with age," American Journal of Obstetrics \& Gynecology, vol. 206, no. 4, pp. 349.e1-349.e7, 2012.

[27] L. Wu, Z.-Y. Dai, Y.-H. Qian, Y. Shi, F.-J. Liu, and C. Yang, "Diagnostic value of serum human epididymis protein 4 (HE4) in ovarian carcinoma: a systematic review and meta-analysis," International Journal of Gynecological Cancer, vol. 22, no. 7, pp. 1106-1112, 2012.

[28] B. Bromley and B. Benacerraf, "Adnexal masses during pregnancy: accuracy of sonographic diagnosis and outcome," Journal of Ultrasound in Medicine, vol. 16, no. 7, pp. 447-454, 1997.

[29] R. Usui, H. Minakami, S. Kosuge, R. Iwasaki, M. Ohwada, and I. Sato, "A retrospective survey of clinical, pathologic, and prognostic features of adnexal masses operated on during pregnancy," Journal of Obstetrics and Gynaecology Research, vol. 26, no. 2, pp. 89-93, 2000.

[30] L. W. Hess, A. Peaceman, W. F. O’Brien, C. A. Winkel, D. P. Cruikshank, and J. C. Morrison, "Adnexal mass occurring with intrauterine pregnancy: report of fifty-four patients requiring laparotomy for definitive management," American Journal of Obstetrics and Gynecology, vol. 158, no. 5, pp. 1029-1034, 1988.

[31] D. N. Platek, C. E. Henderson, and G. L. Goldberg, "The management of a persistent adnexal mass in pregnancy," American Journal of Obstetrics and Gynecology, vol. 173, no. 4, pp. 1236$1240,1995$.

[32] K. Hoover and T. R. Jenkins, "Evaluation and management of adnexal mass in pregnancy," American Journal of Obstetrics and Gynecology, vol. 205, no. 2, pp. 97-102, 2011.

[33] P. Glanc, S. Salem, and D. Farine, "Adnexal masses in the pregnant patient a diagnostic and management challenge," Ultrasound Quarterly, vol. 24, no. 4, pp. 225-240, 2008.

[34] D. Timmerman, A. C. Testa, T. Bourne et al., "Simple ultrasound-based rules for the diagnosis of ovarian cancer," Ultrasound in Obstetrics and Gynecology, vol. 31, no. 6, pp. 681690, 2008.

[35] N. Smorgick and R. Maymon, "Assessment of adnexal masses using ultrasound: a practical review," International Journal of Women's Health, vol. 6, pp. 857-863, 2014.

[36] D. Timmerman, L. Ameye, D. Fischerova et al., "Simple ultrasound rules to distinguish between benign and malignant adnexal masses before surgery: prospective validation by IOTA group," The British Medical Journal, vol. 341, Article ID c6839, 2010.

[37] J. Kaijser, A. Sayasneh, K. Van hoorde et al., "Presurgical diagnosis of adnexal tumours using mathematical models and scoring systems: a systematic review and meta-analysis," Human Reproduction Update, vol. 20, no. 3, pp. 449-462, 2014.

[38] T. C. Wheeler and A. C. Fleischer, "Complex adnexal mass in pregnancy: predictive value of color Doppler sonography," Journal of Ultrasound in Medicine, vol. 16, no. 6, pp. 425-428, 1997.

[39] P. D. DePriest and C. P. DeSimone, "Ultrasound screening for the early detection of ovarian cancer," Journal of Clinical Oncology, vol. 21, supplement 10, pp. 194s-199s, 2003.

[40] M. Yacobozzi, D. Nguyen, and D. Rakita, "Adnexal masses in pregnancy," Seminars in Ultrasound, CT and MRI, vol. 33, no. 1, pp. 55-64, 2012.

[41] Y. Patenaude, D. Pugash, K. Lim et al., "The use of magnetic resonance imaging in the obstetric patient," Journal of Obstetrics and Gynaecology Canada, vol. 36, no. 4, pp. 349-363, 2014.

[42] M. White and J. Stella, "Ovarian torsion: 10-year perspective," Emergency Medicine Australasia, vol. 17, no. 3, pp. 231-237, 2005.

[43] D. Houry and J. T. Abbott, "Ovarian torsion: a fifteen-year review," Annals of Emergency Medicine, vol. 38, no. 2, pp. 156159, 2001.

[44] Z. Tsafrir, J. Hasson, I. Levin, E. Solomon, J. B. Lessing, and F. Azem, "Adnexal torsion: cystectomy and ovarian fixation are equally important in preventing recurrence," European Journal of Obstetrics Gynecology and Reproductive Biology, vol. 162, no. 2, pp. 203-205, 2012.

[45] T. Tobiume, M. Shiota, M. Umemoto, Y. Kotani, and H. Hoshiai, "Predictive factors for ovarian necrosis in torsion of ovarian tumor," The Tohoku Journal of Experimental Medicine, vol. 225, no. 3, pp. 211-214, 2011.

[46] O. Taskin, M. Birincioglu, A. Aydin et al., "The effects of twisted ischaemic adnexa managed by detorsion on ovarian viability and histology: an ischaemia-reperfusion rodent model," Human Reproduction, vol. 13, no. 10, pp. 2823-2827, 1998.

[47] D. Hasiakos, K. Papakonstantinou, A. Kontoravdis, L. Gogas, L. Aravantinos, and N. Vitoratos, "Adnexal torsion during pregnancy: report of four cases and review of the literature," Journal of Obstetrics and Gynaecology Research, vol. 34, no. 4, part 2, pp. 683-687, 2008.

[48] J. Hasson, Z. Tsafrir, F. Azem et al., "Comparison of adnexal torsion between pregnant and nonpregnant women," American Journal of Obstetrics and Gynecology, vol. 202, no. 6, pp. 536.el536.e6, 2010.

[49] A. K. Styer and M. R. Laufer, "Ovarian bivalving after detorsion," Fertility and Sterility, vol. 77, no. 5, pp. 1053-1055, 2002.

[50] N. A. Pavlidis, "Coexistence of pregnancy and malignancy," Oncologist, vol. 7, no. 4, pp. 279-287, 2002.

[51] D. Pereg, G. Koren, and M. Lishner, "Cancer in pregnancy: gaps, challenges and solutions," Cancer Treatment Reviews, vol. 34, no. 4, pp. 302-312, 2008.

[52] M. K. Oehler, G. V. Wain, and A. Brand, "Gynaecological malignancies in pregnancy: a review," Australian and New Zealand Journal of Obstetrics and Gynaecology, vol. 43, no. 6, pp. 414420, 2003.

[53] H. Sayar, C. Lhomme, and C. F. Verschraegen, "Malignant adnexal masses in pregnancy," Obstetrics and Gynecology Clinics of North America, vol. 32, no. 4, pp. 569-593, 2005.

[54] C. C. Kilpatrick and F. J. Orejuela, "Management of the acute abdomen in pregnancy: a review," Current Opinion in Obstetrics and Gynecology, vol. 20, no. 6, pp. 534-539, 2008.

[55] M. B. Reedy, B. Kallen, and T. J. Kuehl, "Laparoscopy during pregnancy: a study of five fetal outcome parameters with use 
of the Swedish Health Registry," American Journal of Obstetrics and Gynecology, vol. 177, no. 3, pp. 673-679, 1997.

[56] P. Mathevet, K. Nessah, D. Dargent, and G. Mellier, "Laparoscopic management of adnexal masses in pregnancy: a case series," European Journal of Obstetrics Gynecology and Reproductive Biology, vol. 108, no. 2, pp. 217-222, 2003.

[57] M.-L. Ko, T.-H. Lai, and S.-C. Chen, "Laparoscopic management of complicated adnexal masses in the first trimester of pregnancy," Fertility and Sterility, vol. 92, no. 1, pp. 283-287, 2009.

[58] A.-S. Azuar, L. Bouillet-Dejou, K. Jardon et al., "Laparoscopy during pregnancy: experience of the French university hospital of Clermont-Ferrand," Gynecologie Obstetrique Fertilite, vol. 37, no. 7-8, pp. 598-603, 2009.

[59] Y. J. Koo, J. Lee, K. Lim, J. Shim, J. Mok, and T. Kim, "A 10-year experience of laparoscopic surgery for adnexal masses during pregnancy," International Journal of Gynecology \& Obstetrics, vol. 113, no. 1, pp. 36-39, 2011.

[60] J. Pearl, R. Price, W. Richardson, and R. Fanelli, "Guidelines for diagnosis, treatment, and use of laparoscopy for surgical problems during pregnancy," Surgical Endoscopy and Other Interventional Techniques, vol. 25, no. 11, pp. 3479-3492, 2011.

[61] H. Marret, C. Lhommé, F. Lecuru et al., "Guidelines for the management of ovarian cancer during pregnancy," European Journal of Obstetrics, Gynecology, and Reproductive Biology, vol. 149, no. 1, pp. 18-21, 2010.

[62] P. Morice, C. Uzan, S. Gouy, C. Verschraegen, and C. HaieMeder, "Gynaecological cancers in pregnancy," The Lancet, vol. 379, no. 9815, pp. 558-569, 2012.

[63] L. Minig, L. Otaño, I. Diaz-Padilla, R. Alvarez Gallego, M. G. Patrono, and J. Valero De Bernabé, "Therapeutic management of epithelial ovarian cancer during pregnancy," Clinical and Translational Oncology, vol. 15, no. 4, pp. 259-264, 2013. 


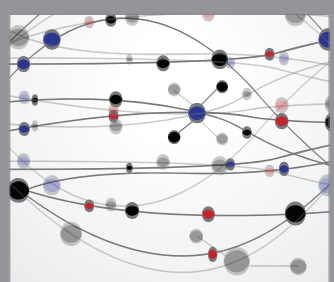

The Scientific World Journal
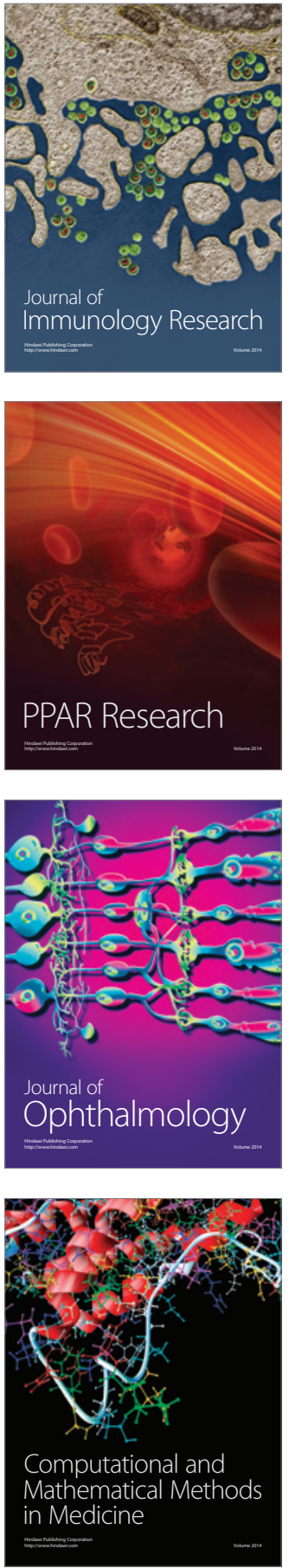

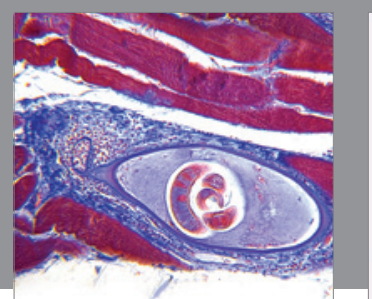

Gastroenterology Research and Practice

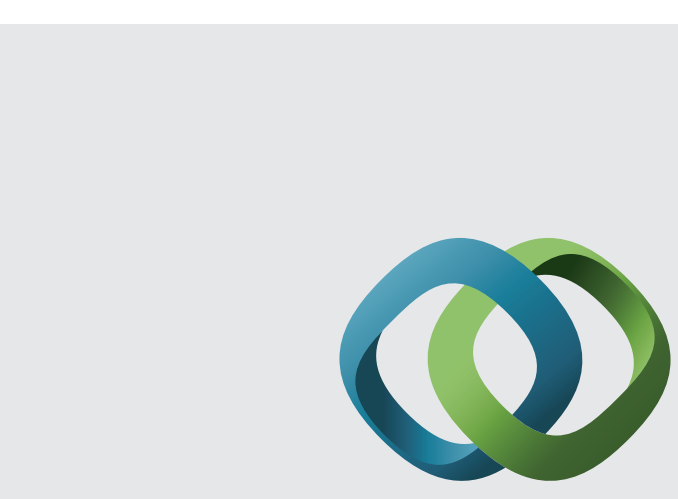

\section{Hindawi}

Submit your manuscripts at

http://www.hindawi.com
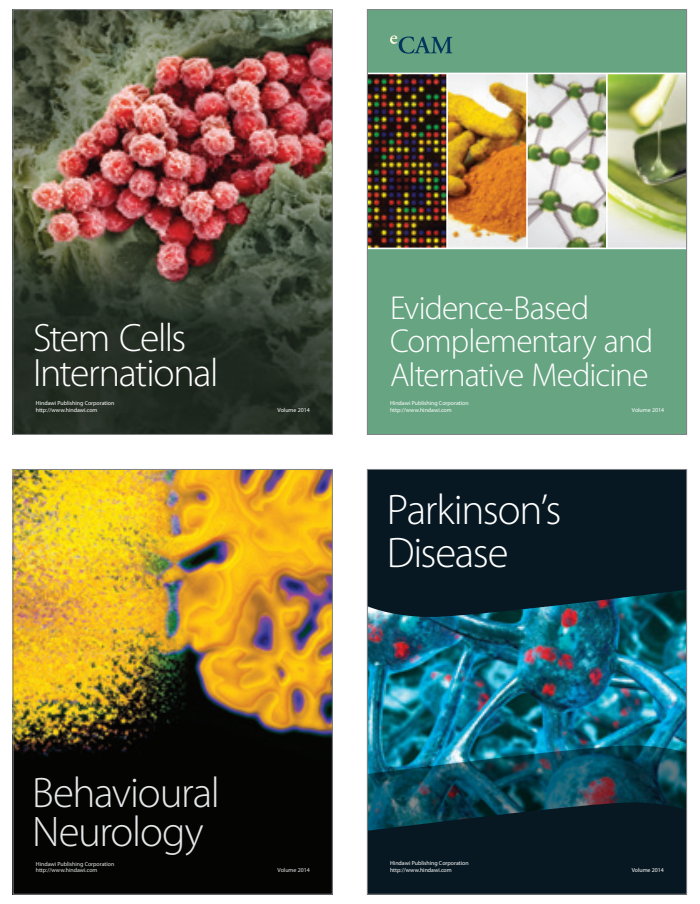
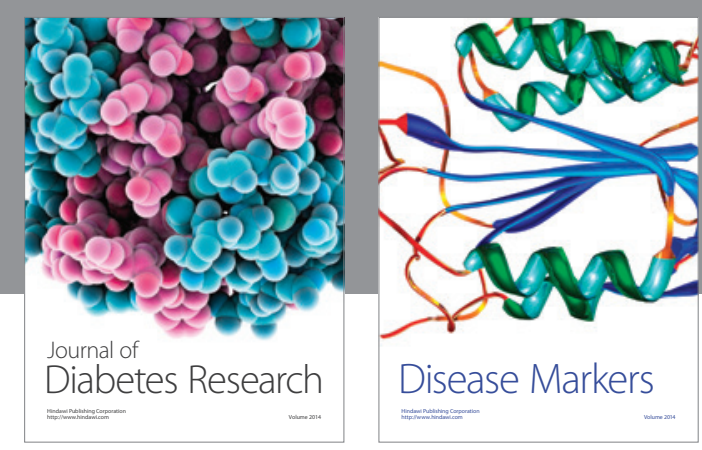

Disease Markers
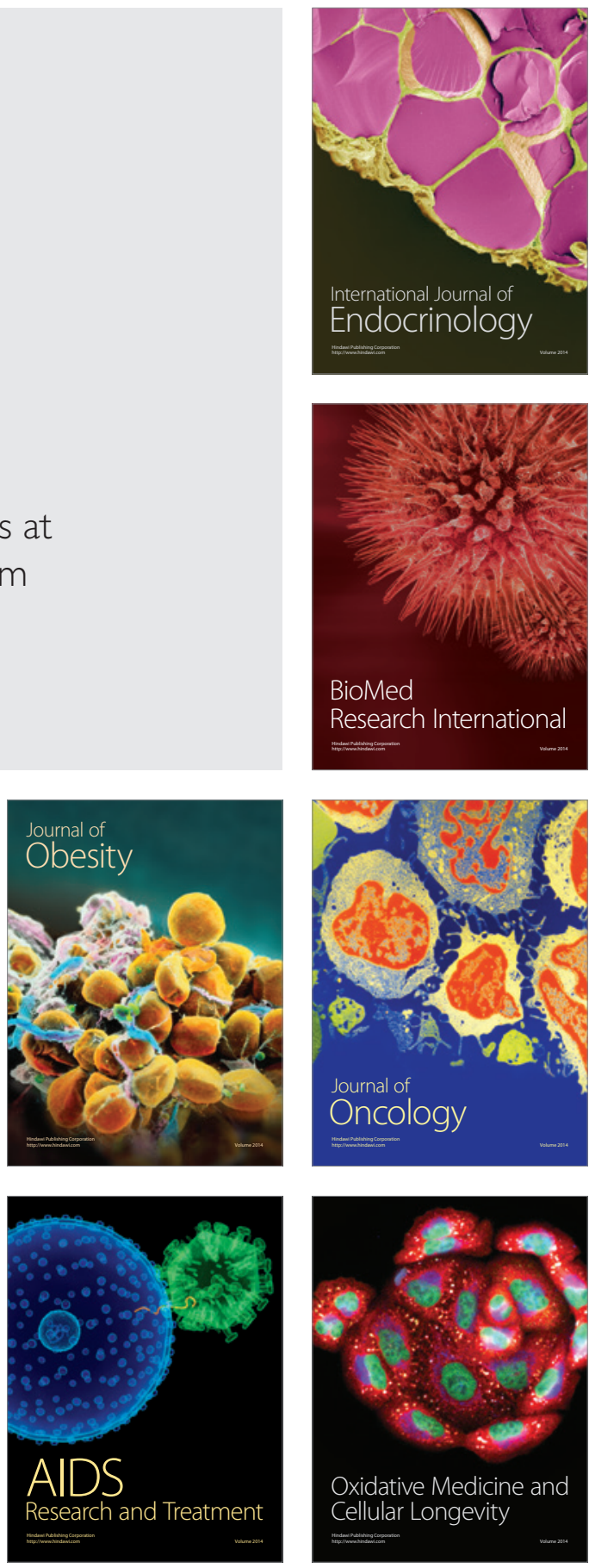